\title{
Los Músicos de Instrumentos de Viento en Contexto de COVID-19. Observaciones y Recomendaciones
}

\author{
Wind Instrument Musicians in the Context of COVID-19. \\ Observations and Recommendations
}

\author{
Rolando Morales-Espinosa $a^{1,2,3}$
}

\begin{abstract}
MORALES-ESPINOZA, R. Los músicos de instrumentos de viento en contexto de COVID-19. Observaciones y recomendaciones. Int. J. Odontostomat., 15(2):325-329, 2021.

RESUMEN: EI COVID-19 ha representado un esfuerzo social por prevenir y prever diferentes escenarios de propagación del virus SARS-CoV-2, donde las actividades culturales han sufrido una disminución en su afluencia, llegando a suspenderse por la alta convocatoria que estos presentan. Los músicos han sido afectados dentro de este contexto, tanto por el cese de su actividad, como por la exposición que pueden sufrir a dicho virus. Especialmente los instrumentos de viento, por su característica ejecución, son vectores de contagio que pueden ser tratados con algunas maniobras de cuidado especial, previniendo la infección en los ejecutantes, permitiendo la continuación de la actividad musical, arte tan vital dentro un contexto tan adverso.
\end{abstract}

PALABRAS CLAVE: SARS-CoV-2, COVID-19, instrumentos de viento, música.

\section{INTRODUCCIÓN}

El coronavirus 2 del Síndrome Respiratorio Agudo Severo (SARS-CoV-2) es un miembro de la familia de los b-coronavirus, con un alto potencial infectivo de los hospederos y en los organismos potencialmente contagiables debido a su alta transmisibilidad, pero de baja letalidad y mortalidad comparativamente al SARSCoV y al coronavirus del Síndrome Respiratorio del Este Medio (MERS-CoV) (Liu et al., 2020; Wang et al., 2020a). Tiene una alta afinidad por los receptores para la enzima convertidora de angiotensina 2 (ACE2) los cuales se encuentran abundantemente en las células del tracto respiratorio y en las células epiteliales que forman los ductos de las glándulas salivales mayores y menores. El virus reconoce este receptor a través de la glicoproteína S1 de su superficie viral, anclándose a esta por su marcada afinidad y tropismo, mientras que a través de su glicoproteína 2 se facilita la fusión del virus a la membrana celular, infectando a las células epiteliales (Lu et al., 2015; Ji et al., 2020; Melián-Rivas et al., 2020; Morales-Espinosa, 2020; Wrapp et al., 2020).
El periodo de incubación del virus es dentro de los 3 primeros días de haber tomado contacto con el agente infectivo. El tiempo promedio entre el inicio de los síntomas y los casos de muerte es de 14 días. En los pacientes mayores de 70 años se ha visto que el período de latencia del virus es significativamente más corto (11,5 días) (Wang et al., 2020a).

Los signos y síntomas de la enfermedad, COVID19 , son agudos, haciéndose evidentes a las 72 horas del contacto con el agente patógeno. El signo más evidente en primera instancia es la fiebre (sobre $37,5^{\circ} \mathrm{C}$ ), seguido por cefaleas y tos persistente. Más tarde aparece la fatiga, mialgia y en algunos casos raros diarrea y vómitos. También se ha informado sobre disfagia, ageusia y anosmia. En etapas más avanzadas pueden verse signos de deficiencias respiratorias mucho más acentuadas como dolor de garganta, expectoración, esputos y disnea, lo cual en algunos casos puede decantar en daños cardíacos agudos y arritmias consecutivos al daño pulmonar (Huang et al., 2020). Un porcentaje no menor de pacientes también presentan

\footnotetext{
${ }^{1}$ Cirujano dentista, especialista en Patología bucomaxilofacial, Servicio de Salud Viña del Mar-Quillota, V región, Chile.

${ }^{2}$ Clarinetista y clarinete bajo, Orfeón Patrimonial De Valparaíso, Valparaíso, Chile.

${ }^{3}$ Profesor de clarinete, 2010-2015, Fundación de Orquestas Juveniles e Infantiles (FOJI), Chile.
} 
daños a nivel hepático (como esteatosis microvesicular) y daños en la función renal, los cuales tienden a la agudización y a la insuficiencia, y juntamente con el daño pulmonar irreparable pueden provocar la muerte (Melián-Rivas et al.; Wang et al., 2020b).

Como ha sido registrado, la sociedad está expuesta de forma masiva a la trasmisión y potencial infección ya que la principal vía de contagio de dicho virus es a través del contacto directo o indirecto con aerosoles, macro y microgotas de saliva o expectoración cargadas con el virus que provengan de un individuo infectado, ya sea por la emisión directa de dichos vehículos a través de funciones respiratorias fisiológicas (acto de hablar, toser, estornudar, etc.) o bien, por el contacto de este paciente con alguna superficie u objeto al manipularlo sin tener las consideraciones de lavarse las manos posterior al contacto con su nariz o boca o bien por expeler los aerosoles directamente sobre la superficie en cuestión (Morales-Espinosa). Dentro de este contexto, entre los diferentes objetos que toman contacto con la saliva, que retienen partículas y pueden ser un medio de contagio potencial son los instrumentos musicales de viento, por lo que esta población de artistas se constituye como un grupo de riesgo donde es necesario apuntar con medidas de protección, higienización acorde al instrumento y su material, además de recomendaciones en la ejecución y almacenamiento.

\section{Características de los instrumentos de viento}

Los instrumentos musicales de viento están constituidos básicamente por un tubo de diferentes secciones y longitudes, fabricados de diversos materiales (sintéticos, metales, maderas o la combinación de todos estos), los cuales al soplar por uno de sus extremos y regular la emisión de la columna de aire con la articulación de la embocadura a través del posicionamiento de labios, lengua y diafragma, sumados a la interferencia del flujo de aire con la colocación ya sea de los dedos directamente o el uso de bombas y pistones propio de los instrumentos de bron$\mathrm{ce}$, se emite un sonido, el cual al conjugarlo con otras articulaciones que producen los diferentes registros, se puede generar lo que entendemos por notas musicales, las cuales al combinarlas melódica y rítmicamente con los silencios dan como resultado la música que proviene de una partitura u obra musical.

La construcción misma del instrumento depende directamente de su arquitectura, timbre, el tono (qué tan agudo o grave es este) y el registro esperado, por lo que la sección del tubo variará en su corte interno, su extensión y su forma, dando lugar a diferentes diseños y conformaciones, observándose formas más bien rectas, como en el caso de flautas, clarinetes $u$ oboes, o curvas, como en el caso de la mayoría de los instrumentos de bronce (trompetas, cornos, trombones y tubas). Esta misma construcción interna de la cámara del instrumento hace que muchas veces la condensación del vapor de aire inyectado dentro del instrumento no tenga la posibilidad de lograr una eficiente salida en la campana de emisión, que es el otro extremo del instrumento y por donde también sale el sonido, por lo que se genera una alta cantidad de residuos de saliva dentro de la cámara del mismo. La emisión de aire con micropartículas a alta presión también puede salir a través de los agujeros de los instrumentos que no están sellados con los dedos, proyectando microgotas hacia el medio ambiente a través de estas secciones, como en el caso de clarinetes, oboes, corno inglés y fagot por ejemplo. Por otra parte, los elementos metálicos que sellan algunos de estos orificios, denominados llaves, tienen unas almohadas de material impermeable en su extremo y que remedan el sellado que debería provocarse con los dedos, y que de no ser correctamente limpiados y secados efectivamente, provocan el deterioro de dicha almohadilla (llamada también "zapatilla"), lo que conlleva a la retención de saliva en estas. Otra zona a considerar donde existe condensación de la saliva misma son los empates o espigas, las secciones donde se une el instrumento al armarlo y que está protegido por corcho, el cual también absorbe el líquido residual del instrumento.

Es de principal reconocimiento que la diferenciación entre instrumentos de viento de madera y bronces hace que las características propias del material del que estén construidos también tengan diferencias en los grados de absorción y retención de partículas, ya que al ser un instrumento de madera este tendrá las vetas internas y las características propias de absorción de las maderas, por más dura que esta sea, como el ébano o el cocobolo. El metal no suele tener este inconveniente ya que no tiene irregularidades macro ni microscópicas que provoquen la retención de saliva en su cámara interna. Sin embargo, la arquitectura propia de los instrumentos de bronce y su sección constituida por elementos curvos que le dan sus características, hacen que la saliva no escurra eficientemente desde dentro del mismo y se libere por la campana de salida, teniendo que recurrir a un émbolo o llave de desagüe que permita eliminar la condensación de saliva desde dentro del instrumento. 
Otro accesorio no menor dentro de la gama de implementos que constituyen estos instrumentos son las lengüetas o cañas. Este es un segmento de caña de bambú cuidadosamente recortado con un diseño especifico y que se coloca en la sección de emisión de aire, denominado boquilla, siendo el elemento fundamental para generar sonido en oboes, fagotes, clarinetes y saxofones, ya que se hace vibrar con el flujo de aire. Por las características propias del material, su grado de absorción de humedad y su alta porosidad, la lengüeta es un artículo que retiene gran parte de los residuos y de saliva del ejecutante, y que de hecho se busca mantener lo más hidratada posible debido a que facilita o da determinadas características en el sonido que busca el músico.

Obviando los elementos de limpieza, que usualmente son paños de diferentes materiales absorbentes para el secado e higienización interna y externa del instrumento, prácticamente todos los elementos implicados en la limpieza y ejecución del instrumento de viento están en contacto con la saliva del ejecutante.

Todos estos eventos y características mencionadas que impliquen la emisión de saliva o de aire expelido por el ejecutante y que sea retenido o proyectado por el instrumento pueden constituir potencialmente una vía de contagio por el SARS-CoV-2 desde un músico contagiado a su audiencia (Becher et al., 2020).

Aerosoles y la práctica musical. En general, los ejecutantes de instrumentos musicales de viento no emiten un flujo de aire directo con la formación de microgotas de saliva sin que previamente pasen por el tubo del instrumento musical, a excepción de los flautistas, cuya técnica de embocadura obliga a la emisión de una columna de aire que se interrumpe por la boquilla, pero que continúa directamente hacia adelante, no pasando completamente hacia el interior del instrumento en el denominado efecto aerodinámico Coanda“, por lo que gran parte de ese flujo de aire cae al ambiente o en el observador que está delante del músico, el cual se puede extender hasta 2 metros desde el origen (Becher et al.; He et al., 2020; Kähler \& Hain, 2020). Para instrumentos que tienen sus campanas en dirección vertical hacia el piso, como clarinetes, el flujo de aire también puede alcanzar esa distancia, pero al ir hacia el piso presenta una circunstancia que podría evitar la emisión directa de aerosoles hacia el oyente (Kähler \& Hain).
Así también, la emisión de aerosoles generadas por los instrumentistas estaría determinada por la técnica de respiración del ejecutante y el diseño del instrumento, observándose menor generación de aerosoles en los ejecutantes de tuba y mayor cantidad de estos en los trompetistas, trombonistas y oboístas, definido por los niveles de dinámica musical y patrones de articulación técnica del instrumento, lo que representaría un mayor riesgo de transmisión eventual del virus a través de la generación de aerosoles (He et al., 2021).

A pesar de lo anterior, y de lo nuevo que representa el desafío de conocer el comportamiento del SARS-CoV-2 en los diferentes contextos, no se dispone de información suficientemente fiable sobre la intensidad con que los instrumentos de viento distribuyen las gotas de saliva en su entorno y qué influencia tienen los flujos de aire interior en el transporte de las gotas (Kähler \& Hain; Public Health Ontario, 2020).

Recomendaciones. Hay que reconocer que en el escenario musical es siempre característico observar como los grupos de artistas se disponen en una posición de elipse alrededor del director, uno al lado del otro, próximos entre sí, formación que se repite en los ensayos y seccionales. Una de las medidas de prevención masivamente extendidas alrededor del mundo es la distancia social, cosa que también se debe hacer extensiva al grupo de músicos, manteniendo un margen de aislamiento de hasta 2 metros entre si, manteniendo la posibilidad de conciertos online o actividades al aire libre con un mínimo público y sólo con algunos instrumentistas, más bien privilegiando piezas solistas o de ensambles de vientos y cuartetos (Kähler \& Hain; Public Health Ontario). Se recomienda también optar por los ensayos individuales o seccionales (sólo un segmento afín del grupo musical) en un espacio lo suficientemente amplio y ventilado, que permita la correcta corriente de aire y mantener la distancia entre los integrantes.

En este contexto, se recomienda el uso de barreras mecánicas entre los instrumentistas y que aíslen al mismo de sus compañeros y del público, sugiriéndose el uso de biombos acrílicos transparentes a modo de cabinas que permitan mantener la calidad escénica del acto musical mismo y que eviten la emisión de gotas y microgotas que expelen los instrumentos hacia sus compañeros de la orquesta o público que esté más adelante. Estas cámaras deben ser sanitizadas y desinfectadas posterior a cada presentación, sugiriéndose como alternativa el uso de panta- 
Ilas transparentes individuales que se adapten al músico y permitan la ejecución del instrumento de forma satisfactoria o la interposición de elementos como papel o sordinas de tela desechables en la campana del instrumento que impidan la eyección de aerosoles (Becher et al.). Así mismo, es conveniente mantener una mascarilla desechable que el músico pueda colocarse posterior a cada intervención musical o cuando su compañero próximo esté desarrollando un pasaje musical.

Por otra parte, es conveniente que los músicos eviten el contacto con los instrumentos de sus compañeros que estén usados o en uso y que no hayan sido limpiados e higienizados previamente, de modo de evitar la contaminación cruzada que se pueda generar al ser el instrumento un vehículo de partículas potencialmente infectivas, las cuales se pueden mantener en la superficie de los instrumentos hasta por 7 horas (van Doremalen et al., 2020). En general, los accesorios no deben ser compartidos (boquillas, lengüetas, botellas de agua, etc.) ni menos aún compartir el instrumento propiamente tal, aunque se haya hecho una eficiente eliminación de la saliva acumulada de manera macroscópica, ya que como se mencionaba anteriormente, la madera o los elementos constitutivos del instrumento pueden retener las partículas infectivas que provengan de la saliva e infectar potencialmente al músico. Dentro de esto, se recomienda la utilización de lengüetas de material sintético, donde la retención de residuos y de saliva es menor. A pesar de que ya no hay producción prácticamente de boquillas de madera particularmente en clarinetes y principalmente son de material resinoso o sintético, la utilización de boquillas de metal (como en el caso de saxofones) o cristal siempre está recomendada para disminuir la aposición de residuos potencialmente infectantes, debido a su pulido interno y las características propias del material.

Se recomienda además que la limpieza del instrumento musical de viento sea realizada por el instrumentista de forma aislada del resto de sus compañeros, evitando el contacto de estos con los elementos de higiene del mismo y que pueden decantar en la trasmisión de saliva.

Para la limpieza de los instrumentos debe ser considerada la utilización de agentes desinfectantes que permitan bajar la carga viral, pero que a la vez preserve la integridad del instrumento musical y sea compatible con las características del material del cual está construido.
La limpieza de instrumentos de metal prácticamente puede ser realizado con cualquier agente desinfectante, siendo muy recomendado el uso de soluciones de agua con jabón cada 5 días y el uso de alcohol isopropílico, sobretodo en la zona de la boquilla, con la utilización de cepillos y paños limpios que posteriormente deben ser lavados. Así mismo puede ser utilizado el mismo método de limpieza en instrumentos de material sintético, como resinas ABS o baquelita, así como en boquillas de metal, cristal o resina. También se recomienda la mezcla de $5 \mathrm{ml}$ de peróxido de hidrógeno 10 vol. y $10 \mathrm{ml}$ de agua destilada para la limpieza interna de instrumentos de madera, ya que el virus del SARS-CoV-2 es vulnerable a la oxidación (Kampf et al., 2020), la cual se puede dejar actuar por 30 minutos y posteriormente proceder a la limpieza con un paño seco de la cámara del instrumento, con la correspondiente humectación con aceite de madera o almendras para evitar la desecación de la madera. Las llaves pueden ser desinfectadas con alcohol o amonio cuaternario no aromático.

Para la desinfección de lengüetas o cañas puede usarse la misma mezcla sumergiéndolas por un lapso de 30 minutos o bien clorhexidina $0,12 \%$, lo cual también evita la formación de hongos y disminuye la desecación que se puede producir por el uso de agentes oxidantes. Como siempre ha sido indicado por los maestros, tener una rotación de lengüetas dentro del portacañas, el cual también debe ser minuciosamente desinfectado con alguno de los agentes anteriormente mencionados y mantenerlos sobre una base de vidrio.

En conclusión, las medidas de mitigación y cese de la cadena de contagio por COVID-19 es un tema transversal a la sociedad y a diferentes actividades, donde la actividad musical no ha sido ajena, por lo que cada maniobra de cuidado, desinfección y limpieza prolija que eviten los vehículos infectivos resultarán en la disminución de casos y con ello superar juntos como sociedad esta pandemia.

AGRADECIMIENTOS. A mis alumnos y amigos de clarinete y compañeros del OPV.

MORALES-ESPINOZA, R. Wind instrument musicians in the context of COVID-19. Observations and recommendations. Int. J. Odontostomat., 15(2):325-329, 2021.

ABSTRACT: COVID-19 has represented a social effort to prevent and anticipate different scenarios for the spread of the SARS-CoV-2 virus, where cultural activities have suffered 
a decrease in their influx, even being suspended due to the high number of people they present. Musicians have been affected within this context, by the cessation of their activity and the exposure they may suffer to said virus. Especially wind instruments, due to their characteristic execution, are vectors of contagion that can be treated with some special care, preventing infection in the performers, allowing the continuation of musical activity, a vital art in an adverse context.

KEY WORDS: SARS-CoV-2, COVID-19, wind instruments, music.
Dirección para correspondencia:

Rolando E. Morales Espinosa

Cirujano Dentista

Clínica Dental Móvil

Hospital Adriana Cousiño, Quintero

Servicio de Salud Viña del Mar- Quillota

Especialista en Patología Oral y Maxilofacial

Universidad de Valparaíso

CHILE

E-mail: rolamoraes@gmail.com

\section{REFERENCIAS BIBLIOGRÁFICAS}

Becher, L.; Gena, A. W. \& Voelker, C. Risk assessment of the spread of breathing air from wind instruments and singers during the COVID-19 pandemic. Weimar, Bauhaus-Universität Weimar, Chair of Building Physics, 2020.

He, R.; Gao, L.; Trifonov, M. \& Hong, J. Aerosol generation from different wind instruments. J. Aerosol Sci., 151:105669, 2021.

Kähler, C. J. \& Hain, R. Singing in choirs and making music with wind instruments - Is that safe during the SARS-CoV-2 pandemic? Munich, Institute of Fluid Mechanics and Aerodynamics, University of the Bundeswehr, 2020. Disponible en:https://www.unibw.de/Irt7-en/making_music_during_the_sarscov-2_pandemic.pdf

Kampf, G.; Todt, D.; Pfaender, S. \& Steinmann, E. Persistence of coronaviruses on inanimate surfaces and their inactivation with biocidal agents. J. Hosp. Infect., 104(3):246-51, 2020.

Liu, Y.; Gayle, A. A.; Wilder-Smith, A. \& Rocklöv, J. The reproductive number of COVID-19 is higher compared to SARS coronavirus. J. Travel Med., 27(2):taaa021, 2020.

Lu, G.; Wang, Q. \& Gao, G. F. Bat-to-human: spike features determining 'host jump' of coronaviruses SARS-CoV, MERS-CoV, and beyond. Trends Microbiol., 23(8):468-78, 2015.

Melián-Rivas, A.; Calcumil-Herrera, P.; Boin-Bakit, C. \& CarrascoSoto, R. Detection of COVID-19 (SARS-CoV-2) by saliva: a lowinvasive diagnostic alternative. Int. J. Odontostomat., 4(3):31620, 2020.

Morales-Espinosa, R. Saliva as a bio-sample for diagnosis SARSCoV-2 Infection: A review. Int. J. Odontostomat., 14(3):327-30, 2020.

Public Health Ontario. COVID-19 Transmission Risks from Singing and Playing Wind Instruments-What We Know So Far 1. Ontario, Public Health Ontario (PHO), 2020.

van Doremalen, N.; Bushmaker, T.; Morris, D. H.; Holbrook, M. G.; Gamble, A.; Williamson, B. N.; Tamin, A.; Harcourt, J. L.; Thornburg, N. J.; Gerber, S. I.; et al. Aerosol and surface stability of SARS-CoV-2 as compared with SARS-CoV-1. N. Engl. J. Med., 382(16):1564-7, 2020.

Wang, L.; Wang, Y.; Ye, D. \& Liu, Q. Review of the 2019 novel coronavirus (SARS-CoV-2) based on current evidence. Int. J. Antimicrob. Agents, 55(6):105948, 2020a.

Wang, W.; Tang, J. \& Wei, F. Updated understanding of the outbreak of 2019 novel coronavirus (2019-nCoV) in Wuhan, China. J. Med. Virol., 92:441-7, 2020b.

Wrapp, D.; Wang, N.; Corbett, K. S.; Goldsmith, J. A.; Hsieh, C. L.; Abiona, O.; Graham, B. S. \& McLellan, J. S. Cryo-EM structure of the 2019-nCoV spike in the prefusion conformation. Science, 367(6483):1260-3, 2020. 